\title{
Urocortin increases the expression of heat shock protein 90 in rat cardiac myocytes in a MEK1/2-dependent manner
}

\author{
B K Brar, J Railson, A Stephanou, R A Knight ${ }^{1}$ and D S Latchman \\ Medical Molecular Biology Unit, Institute of Child Health, 30 Guilford Street, London WC1N 1EH, UK \\ ${ }^{1}$ Department of Cystic Fibrosis, National Heart and Lung Institute, Emmanuel Kaye Building, Manresa Road, London SW3 6LR, UK \\ (Requests for offprints should be addressed to D S Latchman; Email: d.latchman@ich.ucl.ac.uk)
}

\begin{abstract}
We have previously demonstrated that urocortin protects cultured cardiac myocytes from ischaemic and reoxygenation injury and decreases the infarct size in the rat heart exposed to regional ischaemia and reperfusion. Urocortin-mediated cardioprotection is via activation of the mitogen-activated protein kinase (MAP kinase, MEK1/2) pathway. In addition, it is well documented that heat shock protein (hsp) 70 and hsp90 are cardioprotective against lethal stress. In this study we show, for the first time, that urocortin induces the expression of hsp 90 but not hsp70 in primary cultures of rat neonatal cardiac myocytes. Levels of hsp90 protein increase by 1.5 -fold over untreated cells within $10 \mathrm{~min}$ of urocortin treatment and are sustained for $24 \mathrm{~h}$ with a maximal increase of $2 \cdot 5$-fold at $60 \mathrm{~min}(P<0.05$ at all time points). The
\end{abstract}

increase in hsp90 expression by urocortin was not inhibited by actinomycin D, and urocortin failed to increase hsp 90 promoter activity. Urocortin induction of hsp90 was inhibited by the MEK1/2 inhibitor PD98059 $(P<0 \cdot 001)$ and by cycloheximide, and both inhibitors abrogate urocortin-mediated cardioprotection $(P<0.05$ for cycloheximide, $P<0.001$ for PD98059). Hence, MEK1/2 and protein synthesis are involved in the cardioprotective effect of urocortin against hypoxic-mediated cell death, possibly due to an increase in expression of hsp90 protein. This is the first report of heat shock protein induction by urocortin or any other member of the corticotrophin-releasing hormone family.

Journal of Endocrinology (2002) 172, 283-293

\section{Introduction}

Urocortin (UCN) is a 40 amino acid peptide that belongs to the corticotrophin-releasing factor (CRF) family of peptides which mediate the action of the hypothalamicpituitary-adrenal axis in response to stress (Vale et al. 1981). Both UCN mRNA and protein are expressed in the rat heart (Okosi et al. 1998, Brar et al. 1999a) and the UCN selective receptor CRF-R2 $\beta$ is specifically expressed in rat heart and skeletal muscle (Vaughan et al. 1995). UCN is a potent cardioprotective agent against simulated hypoxic/ischaemic injury both ex vivo and in vitro, with the cardioprotective effect mediated by the mitogen-activated protein (MAP) kinase (MEK1/2) signalling pathway (Brar et al. 2000). This protective effect can be observed using a variety of assays for cell death/apoptosis, including trypan blue exclusion, lactate dehydrogenase release (Brar et al. 1999a), TUNEL staining and annexin-V surface staining (Brar et al. 2000). Studies in our laboratory have shown that cardiotrophin-1 (CT-1), a member of the interleukin-6 family of cytokines, is cardioprotective against hypoxic/ischaemic stress (Stephanou et al. 1998). CT-1 also mediates its

cardioprotective effect by activating the MEK1/2 pathway and increases the synthesis of heat shock protein (hsp) 70 and hsp90 (Stephanou et al. 1998, Brar et al. 2001).

Heat shock proteins increase in synthesis in response to stress and help to maintain cellular homeostasis by promoting the correct folding of proteins, hence acting as molecular chaperones, repairing denatured proteins or promoting their degradation (Benjamin \& McMillan 1998). In the heart, a major physiological stress is hypoxia/ ischaemia and both hsp27 (hsp 27/25) and hsp70 have been implicated as cardioprotective agents against hypoxic stress (Brar et al. 1999b). Hsp70 expression induced by thermal or ischaemic preconditioning reduces infarct size in animal models (Marber et al. 1993, 1995, Plumier et al. 1995). Over-expression of hsp70 confers a cytoprotective effect on cultured cells, including cardiac myocytes subjected to simulated ischaemia (Mestril et al. 1994, Martin et al. 1997). Specifically, the over-expression of hsp70 in transgenic mice improves myocardial function (Radford et al. 1996) and metabolic recovery (Plumier et al. 1995) and reduces infarct size following ischaemia reperfusion (Hutter et al. 1996). The hsp90 family of heat shock proteins makes up $1-2 \%$ of total soluble cytoplasmic 
protein and exists in two forms: hsp $90 \alpha$ and hsp $90 \beta$. Hsp90 forms a complex with hsp70 and hsp56 and the steroid receptors (Denis \& Gustafsson 1989). Overexpression of hsp $90 \beta$ has been shown to protect cardiac cells from lethal heat stress only and not from hypoxic injury (Heads et al. 1995), although hsp90 protein expression has been shown to increase in ischaemic myocardium (Heads et al. 1995, Cumming et al. 1996).

The rapid induction of heat shock proteins occurs through mechanisms of preferential transcriptional activation and translation (Nakai et al. 1995). Heat shock factors (HSFs) are transcription factors that bind to the heat shock response element (HSE) found in the promoters of heat shock genes. Multiple forms of HSFs have been identified in mice and humans, although it is HSF1 that is hyperphosphorylated in a ras-dependent manner by members of the MAP kinase subfamilies (extracellular receptor kinase 1/2 (ERK1/2)), stress activated protein kinase (SAPKs, JNKs) and p38 protein kinase in response to physiological stresses including hypoxia (Kim et al. 1997).

Under non-stressed conditions, both DNA binding activity and transcriptional activity of vertebrate HSF1 are under tight negative control, possibly by binding to hsp70, hsp90 or unknown inhibitory factors which result in stress-inducible activation and rapid deactivation of HSF1 (Xiao \& Lis 1988). Physiological stresses, such as heat and ischaemia, induce HSF1 monomers to oligomerise as homotrimers, which then bind to the HSE motif in the promoters of all stress inducible genes (Metz et al. 1996). Hence, activation of HSF1 does not require new protein synthesis. Heat shock proteins are also expressed in unstressed cells and their levels are regulated in response to a wide variety of biological processes such as T-lymphocyte activation (Teshima et al. 1996). In general, however, the stimuli that induce hsp gene expression under non-stressed conditions have been poorly characterised and the mechanisms by which they interact with the stress response are unclear. Strategies that increase the rate of physiological recovery after myocardial infarction are of therapeutic importance as methods such as whole body hyperthermia are impractical and cumbersome. Hence, pharmacological methods that increase stress protein expression have potential merit in protecting against ischaemic damage to the heart.

We have previously shown that UCN protects cardiac myocytes from hypoxic injury by activating the MEK1/2 signalling pathway (Brar et al. 2000). In addition, CT-1 has been shown to be both cardioprotective by activating the MEK1/2 signalling pathway and to induce hsp70 and hsp90 protein expression (Stephanou et al. 1998). We therefore investigated whether UCN mediates its cardioprotective effect by increasing the expression of cytoprotective hsps and if UCN-mediated cardioprotection requires protein synthesis in general. Following findings that the MEK1/2 inhibitor, PD98059, inhibits UCNmediated cardioprotection, we investigated whether
PD98059 had any effect on hsp induction by UCN and whether the UCN increase in hsps was a transcriptional or a post-transcriptional regulated event.

\section{Materials and Methods}

\section{Antibodies and reagents}

Culture media (Dulbecco's modified Eagle's medium; DMEM), penicillin/streptomycin, versene, L-glutamine, pancreatin, trypsin-EDTA solution, and fetal calf serum (FCS) were purchased from GIBCO BRL (Uxbridge, Middlesex, UK). Collagenase type 2 was obtained from Worthington Biochem (Reading, UK). Sterile tissue culture apparatus was obtained from Falcon Marathon Lab Supplies (London, UK). Enhanced chemiluminescence (ECL) kit was obtained from Amersham, Pharmacia Biotech UK Ltd (Amersham Place, Little Chalfont, Bucks, UK). $5 \% \mathrm{CO}_{2}, 0 \% \mathrm{O}_{2}$, balance gas $\mathrm{N}_{2}$ was obtained from BOC Gases (BOC Ltd Speciality Gases, London, UK). Hybond $\mathrm{C}$ nitrocellulose membrane was obtained from Amersham, Pharmacia Biotech UK Ltd. All other chemicals and reagents were obtained from Sigma (Poole, Dorset, UK), unless otherwise stated.

A mouse monoclonal antibody (AC88) which specifically reacts with hsp90 was kindly provided by Dr D O Toft, Department of Biochemistry and Molecular Biology, Mayo Graduate School, Rochester, MN, USA and has been used previously (Redmond et al. 1989). This antibody detects both hsp $90 \alpha$ and hsp $90 \beta$. Anti-hsp72 (inducible form) was obtained from Stressgen (Victoria, BC, Canada) (SPA-810).

The antibody to actin (1-19):Sc-1616 is a goat polyclonal antibody that is raised to an epitope mapping at the carboxyl terminus of actin of human origin and is reactive with a broad range of actin isoforms from mouse, rat and human (Insight Biotechnology, London, UK). An antibody directed to phosphorylated ERK1/2, p42/44 MAP kinases and an antibody directed to ERK2 (detects both ERK1/2, p42/44, unphosphorylated and phosphorylated kinases) were obtained from Promega (Madison, WI, USA). Secondary antibodies, horse radish peroxidaseconjugated anti-mouse and anti-rabbit IgG and antigoat IgG were obtained from DAKO A/s, Copenhagen, Denmark. For Western blot analysis all primary antibodies were used at a dilution of $1 / 1000$. Secondary antibodies were used at a dilution of $1 / 2000$.

\section{Preparation of neonatal rat cardiac myocyte cultures}

Ventricular myocytes were isolated from the hearts of neonatal rats (Sprague Dawley) less than 2 days old, and were cultured as described previously (Simpson \& Savion 1982). Cells were plated on 24-well, 1-cm diameter plates for experiments involving assessment of cell death, 
and 6-well, 3-cm diameter plates for experiments of transfection and Western blot analysis. After $24 \mathrm{~h}$ from plating, the cell media were replenished with the above media containing reduced FCS at $1 \%(\mathrm{v} / \mathrm{v})$ for an additional $24 \mathrm{~h}$ before experimentation (hereafter referred to as growth medium). Within 2 days of preparation, a confluent monolayer of spontaneously beating myocytes was formed.

\section{Treatment of cells}

Recombinant rat UCN peptide (Sigma) was used at a concentration of $10^{-8} \mathrm{M}$ unless otherwise stated. The MEK1/2 inhibitor (PD98059, PD) was purchased from New England Biolabs, Inc., Beverly, MA, USA and has been shown to act as a highly selective inhibitor of MEK1/2 activation and the ERK1/2, p42/44 MAP kinase cascade (Dudley et al. 1995). PD was used at a concentration of $50 \mu \mathrm{M}$ and was added for $30 \mathrm{~min}$ prior to the treatment with UCN, as stated by New England Biolabs, to inhibit MEK1/2 activity. Pre-treatment of cardiac myocytes with PD98059 failed to affect the p38 or the JNK pathway by Western blot analysis using phosphospecific antibodies (New England Biolabs). The RNA synthesis inhibitor, actinomycin D (ACT) was added to cells $30 \mathrm{~min}$ prior to UCN treatment and used at a concentration of $5 \mu \mathrm{g} / \mathrm{ml}$. Cycloheximide (CYC), an inhibitor of protein synthesis, was used at a concentration of $1 \mu \mathrm{g} / \mathrm{ml}$ (Sigma) and added before treatment with UCN.

\section{Induction of hsp 90 protein expression by UCN}

Cardiac myocytes were cultured in serum-free media for $24 \mathrm{~h}$ at $37^{\circ} \mathrm{C}$ in a humidified atmosphere of $5 \% \mathrm{CO}_{2}, 21 \%$ $\mathrm{O}_{2}$ (normoxic environment) and treated with UCN for $10,20,40,60,120,360 \mathrm{~min}$ and $24 \mathrm{~h}$. UCN at concentrations of $10^{-7} \mathrm{M}, 10^{-8} \mathrm{M}, 10^{-9} \mathrm{M}$, and $10^{-10} \mathrm{M}$ was cultured with the cardiac myocytes for a period of $60 \mathrm{~min}$. Cells were harvested immediately in $200 \mu \mathrm{l}$ ice-cold lysis buffer containing $0 \cdot 1 \%(\mathrm{v} / \mathrm{v})$ 2-mercaptoethanol, $0 \cdot 01 \%$ (v/v) Triton-X-100, $1 \mathrm{mM}$ EDTA, $1 \mathrm{mM}$ EGTA, $10 \mathrm{mM}$ Tris $\mathrm{pH} 7 \cdot 4,0 \cdot 2 \mathrm{mM}$ sodium vanadate, $0 \cdot 2 \mathrm{mM}$ phenyl methyl sulphonylfluoride. An aliquot of cell lysate $(5 \mu \mathrm{l})$ was retained to measure cell protein content so that equal amounts of protein were separated for each treatment on SDS-PAGE (Pierce, Rockford, IL, USA; Coomassie blue protein assay reagent, G250 based). Cellular proteins were re-suspended in an equal volume of $2 \times$ sample treatment buffer (STB; $100 \mathrm{mM}$ Tris ( $\mathrm{pH}$ 6.8), $200 \mathrm{mM}$ dithiothreitol, 4\% (w/v) SDS, $0 \cdot 2 \%$ (w/v) bromophenol blue, 20\% (w/v) glycerol). The samples were boiled for 3 min and proteins were electrophoresed on a $12 \%$ SDS-PAGE gel and were subsequently transferred onto hybond $\mathrm{C}$ nitrocellulose membranes and then probed for $2 \mathrm{~h}$ at room temperature using antibodies specific for hsp90, hsp70 and actin. The membranes were washed in PBS $/ 0 \cdot 05 \%(\mathrm{v} / \mathrm{v})$ Tween and incubated with a peroxidase-conjugated antibody. Immunoreactive bands were visualised by ECL. The relative protein levels were normalised relative to the actin band. To confirm that PD inhibits p42/44 phosphorylation, UCN was incubated with cardiac myocytes for $10 \mathrm{~min}$ in the presence and absence of PD. The cell lysates were subjected to Western blot analysis and probed with an antibody that detects phosphorylated ERK1/2, p42/44 and an antibody directed to ERK2.

To determine whether UCN induction of hsp90 protein expression is via the MEK1/2 signalling pathway, UCN was incubated with the cardiac myocytes for $24 \mathrm{~h}$ with and without PD98059 pre-treatment. In addition, UCN at concentrations of $10^{-7} \mathrm{M}, 10^{-8} \mathrm{M}, 10^{-9} \mathrm{M}$, $10^{-10} \mathrm{M}$ was cultured with the cardiac myocytes for 60 min with pretreatment with PD98059. Cell extracts were subjected to SDS-PAGE immunoblot analysis using the hsp90 and actin antibodies, as described above. To determine the effect of CYC on hsp 90 protein synthesis by $\mathrm{UCN}, \mathrm{CYC}$ was incubated with the cells prior to a 1-h incubation with UCN. Cells were then harvested for SDS-PAGE immunoblot analysis as described above. To determine whether the UCN-induced increase in expression of hsp90 protein is transcriptionally or posttranscriptionally regulated, cardiac myocytes were treated with the RNA synthesis inhibitor ACT for $1 \mathrm{~h}$ prior to treatment with UCN. The cells were harvested as described above and subjected to Western blot analysis for hsp90 and hsp70. Immunoblots were scanned for increases in protein expression using an Epson Perfection 1200 photoscanner and a Gene Tools from Syn Gene/ Merck (Leicestershire, UK). Hsp90 levels were equalised to actin levels. All Western blots were repeated a minimum of three times with independent samples.

\section{Transfection of hsp $90 \alpha$ and $h s p 90 \beta$ promoters}

The $5^{\prime}$ hsp $90 \beta$ promoter chloramphenicol acetyl transferase (CAT) reporter construct hsp90 $\beta$ was a kind gift from Dr Neil Rebbe (Washington University School of Medicine, St Louis, MO, USA; Rebbe et al. 1987). Hsp90 $\beta$ CAT construct consists of a fragment -1044 to +36 relative to the transcriptional start site coupled to a CAT vector. The $5^{\prime}$ hsp $90 \alpha$ CAT consists of a fragment -1050 to +42 relative to the transcriptional start site, coupled to a CAT vector (Hickey et al. 1989). Transient transfections were performed using a calcium phosphate method in 6-well plates. Briefly, $5 \mu \mathrm{g}$ CAT reporter plasmid and $2 \mu \mathrm{g} \beta$ galactosidase (B-gal) expression vector were co-transfected overnight. As a negative control an additional transfection using the $\mathrm{PBLCAT}_{2}$ expression vector (Promega) was performed.

After the transfection, growth media were replaced with fresh growth media and the cells were incubated with 
UCN for 2 or $24 \mathrm{~h}$. As positive controls the cardiac myocytes transfected with both promoters were subjected to 30 min of heat shock at $43^{\circ} \mathrm{C}$ using pre-warmed media and cultured for $24 \mathrm{~h}$ in a normoxic environment at $37^{\circ} \mathrm{C}$ to allow expression of CAT. The cells were recovered by treatment with $1 \mathrm{mM}$ EDTA and lysed by freezethawing. Assays for CAT activity (with assay time of $60 \mathrm{~min}$ ) were performed according to the method of Gorman (1985) using samples of equal protein concentration, previously determined by the method of Bradford (1976). To control for differences in transfection efficiency, results of CAT activity were corrected for B-gal activity in the same transfection. To determine transfection efficiency, $5 \mu \mathrm{g}$ B-gal expression plasmid was transfected overnight into cardiac myocytes. Cells were allowed to express the gene for $24 \mathrm{~h}$, fixed with $1 \%(\mathrm{w} / \mathrm{v})$ paraformaldehyde solution in PBS and stained with X-gal as described previously (Stephanou et al. 2000). The number of blue stained B-gal expressing cells is expressed over the total number of cells to determine the transfection efficiency, which was calculated at between $5 \%$ and $7 \%$.

Treatment of cardiac myocytes with UCN prior to ischaemic injury

PD98059, CYC and ACT were incubated with the cardiac myocytes prior to a 1 - and 24-h pre-treatment with UCN. The cells were exposed to a 6-h lethal simulated hypoxic ischaemic insult and cell survival was assessed by trypan blue exclusion as described previously (Brar et al. 2000). We have previously demonstrated that UCN prevents both apoptotic and necrotic cell death and found that trypan blue exclusion is an efficient method for measuring total cell survival (Brar et al. 1999a).

Exposure of cardiac myocytes to lethal simulated hypoxia/ischaemia

For lethal simulated hypoxic/ischaemic treatment, growth media was replaced with Esumi ischaemic buffer containing $137 \mathrm{mM} \mathrm{NaCl}, 12 \mathrm{mM} \mathrm{KCl}, 0.49 \mathrm{mM} \mathrm{MgCl}$, $0.9 \mathrm{mM} \mathrm{CaCl}_{2} \cdot 2 \mathrm{H}_{2} \mathrm{O}, 4 \mathrm{mM}$ HEPES, $10 \mathrm{mM}$ deoxyglucose, $20 \mathrm{mM} \mathrm{Na}$ lactate $(\mathrm{pH} 6 \cdot 2)$ as described previously (Esumi et al. 1991). The cells were incubated in the hypoxic/ischaemic chamber at $37{ }^{\circ} \mathrm{C}$ for $6 \mathrm{~h}$ in a humidified atmosphere of $5 \% \mathrm{CO}_{2}, 0 \% \mathrm{O}_{2}$, balance gas $\mathrm{N}_{2}$ at a pressure of $4 \mathrm{lb} /$ inch $^{3}$. Untreated cells were cultured in Esumi control buffer in a humidified atmosphere of $5 \% \mathrm{CO}_{2}, 21 \% \mathrm{O}_{2}$, at $37^{\circ} \mathrm{C}$ for $6 \mathrm{~h}$ as internal controls for this experiment. Modified Esumi control buffer consists of $137 \mathrm{mM} \mathrm{NaCl}, 3 \cdot 8 \mathrm{mM} \mathrm{KCl}, 0 \cdot 49 \mathrm{mM}$ $\mathrm{MgCl}_{2}, 0 \cdot 9 \mathrm{mM} \mathrm{CaCl}_{2} \cdot 2 \mathrm{H}_{2} \mathrm{O}, 4 \mathrm{mM}$ HEPES and $10 \mathrm{mM}$ glucose $(\mathrm{pH} 7 \cdot 4)$.

\section{Statistics}

Data for in vitro experiments are expressed as means \pm S.D. Two-way ANOVA was performed for each group of
Untreated cells UCN (1 X $\left.10-{ }^{8} \mathrm{M}\right)$

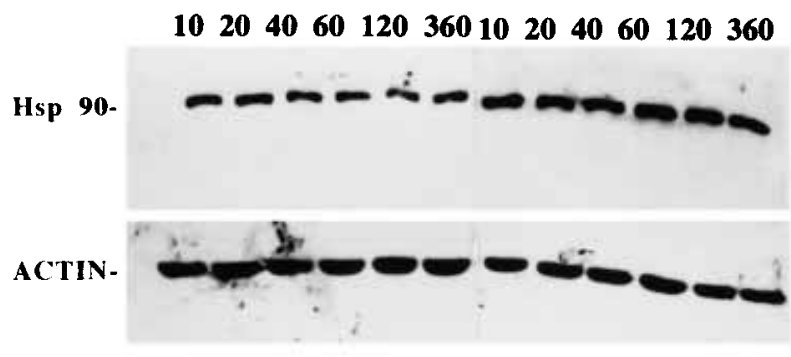

\section{Untreated cells}

$\mathrm{UCN}\left(10-{ }^{-1} \mathrm{M}\right)$

$\begin{array}{llllllllllll}10 & 20 & 40 & 60 & 120 & 360 & 10 & 20 & 40 & 60 & 120 & 360\end{array}$

Hsp 70-

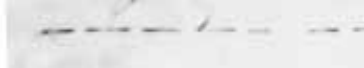

Figure 1 Induction of heat shock protein (hsp)90 protein by urocortin (UCN). UCN peptide was cultured with neonatal cardiac myocytes for 10, 20, 40, 60, 120 and 360 min. Untreated cells and $\mathrm{UCN}$-treated cells were harvested and total cellular proteins were subjected to SDS-PAGE Western blot analysis (see Experimental procedures) using antibodies specific for hsp90, actin and hsp70.

treatments and significance was assumed when the $P$-value was less than $0 \cdot 05$. Differences among means were compared within the treatment groups using a Post-Hoc test. For cell survival observations, each $n$ number is representative of the mean of 6 counts per well. Therefore an $n$ number of 8 is equal to 8 wells and therefore 48 counts.

\section{Results}

\section{Induction of hsp90 protein by UCN}

Heat shock proteins protect cardiac cells from lethal ischaemic injury (Brar et al. 1999b, Marber et al. 1993, 1995, Plumier et al. 1995). To investigate whether UCN induces the expression of cytoprotective hsp90 and hsp70, UCN peptide was cultured with neonatal cardiac myocytes for 10, 20, 40, 60, 120 and $360 \mathrm{~min}$. Unstimulated cells and UCN-treated cells were harvested and total cellular proteins were subjected to SDS-PAGE Western blot analysis using antibodies specific for hsp90 and hsp70. UCN increased hsp90 protein levels compared with untreated cells by 1.5 -fold at $10 \mathrm{~min}, 1 \cdot 5$-fold at $20 \mathrm{~min}$, $1 \cdot 9$-fold at $40 \mathrm{~min}, 2 \cdot 5$-fold at $60 \mathrm{~min}, 2 \cdot 4$-fold at $120 \mathrm{~min}$ and 1.6-fold at $360 \mathrm{~min}$ of treatment $(P<0.05$ for all treatments) (Fig. 1). As expected, the levels of hsp70 were very low in the untreated cells since the antibody used 

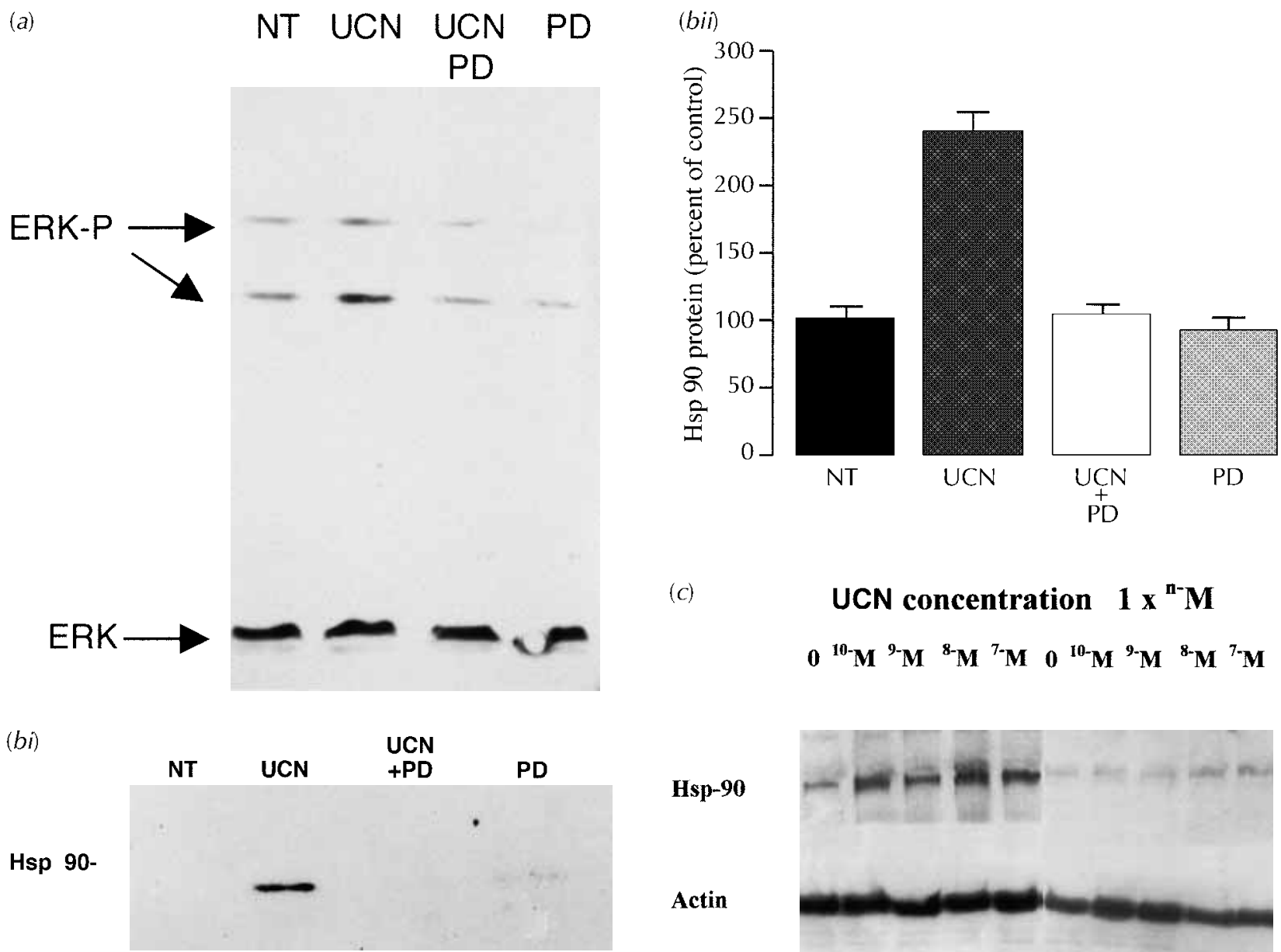

PD

(c)

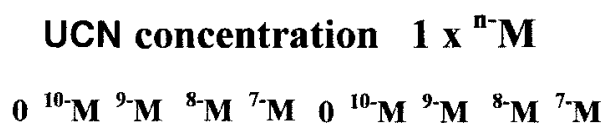

Hsp-90

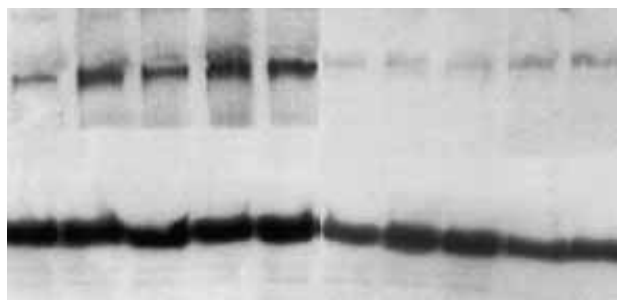

Figure 2 (a) PD98059 (PD) abolishes phosphorylation of ERK1/2, p42/44 MAP kinase by UCN. UCN was incubated with cardiac myocytes for $10 \mathrm{~min}$ in the presence (UCN+PD) and absence of PD (UCN). Cells were also subjected to no treatment (NT) or PD treatment alone (PD). Cell lysates were subjected to SDS-PAGE Western blot analysis and separate immunoblots probed with antibodies directed to phosphorylated ERK1/2, p42/44 (ERK-P) and total ERK (ERK). (b) A 24 h pre-treatment with UCN increases hsp90 protein expression and this is inhibited by inhibiting the MEK1/2 pathway. UCN was incubated with cardiac myocytes for $24 \mathrm{~h}$ with (UCN+PD) and without PD (UCN). Cells were also left untreated (NT) and treated with PD alone (PD). Total cellular proteins were subjected to SDS-PAGE Western blot analysis (see Materials and Methods) using an antibody specific for hsp90. Panel (i) shows a typical blot and panel (ii) the result of densitometric scanning of three blots. (c) Dose-response of UCN induction of hsp90 is inhibited by $50 \mu \mathrm{M}$ PD. $\mathrm{UCN}$, at concentrations of $10^{-10} \mathrm{M}$ to $10^{-7} \mathrm{M}$, was incubated with cardiac myocytes for $1 \mathrm{~h}$, with (left, 5 lanes) and without (right, 5 lanes) PD. Cell lysates were subjected to SDS-PAGE Western blot analysis and probed with hsp90 antibody.

specifically recognises the inducible form of the protein. The levels of inducible hsp70 protein were not significantly increased by UCN (Fig. 1).

\section{UCN increase in hsp 90 protein expression is mediated by} MEK1/2

We have previously shown that UCN mediates cardioprotection by activating the MEK1/2 signalling pathway (Brar et al. 2000). PD is a specific inhibitor of MEK1/2 which is the upstream activator of ERK1/2, p42/44 MAP kinases. UCN was incubated with cardiac myocytes for $10 \mathrm{~min}$ in the presence and absence of PD. Cell extracts were separated using 12\% SDS-PAGE and probed with antibodies specific to phosphorylated and total ERK2. As shown in Fig. 2a, PD completely abolishes phosphorylation of p42/44 MAP kinases by UCN indicating that the inhibitor was working effectively in our system.

To determine whether the UCN increase in hsp90 protein expression is via activation of MEK1/2, UCN was incubated with the cardiac myocytes for $24 \mathrm{~h}$ with and without pre-treatment with $50 \mu \mathrm{M}$ PD. UCN induced the expression of hsp 90 protein following $24 \mathrm{~h}$ incubation but the levels of hsp90 induced by UCN were significantly reduced in the presence of PD $(P<0 \cdot 001)$ (Fig. 2b). A similar inhibition of increase in hsp90 was observed 
Table 1 Relative fold increase (mean value \pm S.D.) in hsp90 protein expression induced by UCN in the presence or absence of PD98059 UCN concentration $(M)$

\begin{tabular}{|c|c|c|c|c|c|c|c|c|}
\hline & 0 & $10^{-12}$ & $10^{-11}$ & $10^{-10}$ & $10^{-9}$ & $10^{-8}$ & $10^{-7}$ & $P$ value \\
\hline
\end{tabular}

The fold increase in hsp90 protein expression with urocortin (UCN) has been summarised. Three independent immunoblots were scanned using an Epson 1200 Scanner and fold induction is presented. The fold changes in hsp90 were compared to the untreated cells (0 UCN concentration) and the data analysed by two-factor ANOVA to compare $+\mathrm{PD}$ and $-\mathrm{PD}$ groups $\left(P\right.$ value $\left.2 \cdot 1 \times 10^{-12}\right)$. Single factor ANOVA has been used to compare data within the $-\mathrm{PD}$ or $+\mathrm{PD}$ group to show significant differences of hsp90 expression in UCN-treated samples compared with the 0 UCN-treated samples.

following a 1-h incubation with UCN and pre-treatment with PD. Additional studies have shown that $5 \mu \mathrm{M}$ PD is sufficient to inhibit the UCN-mediated increase in hsp90 protein, and this concentration also inhibits the UCN cardioprotective effect against simulated ischaemia reoxygenation (Brar et al. 2000, data not shown).

To test the dose-response to UCN, the peptide at concentrations of $10^{-7} \mathrm{M}, 10^{-8} \mathrm{M}, 10^{-9} \mathrm{M}$ and $10^{-10} \mathrm{M}$ was incubated with the cardiac myocytes for 60 min with and without pre-treatment with PD98059. Cell extracts were subjected to SDS-PAGE immunoblot analysis using the hsp90 and actin antibodies (Fig. 2c). UCN increased the expression levels of hsp90 at all concentrations $\left(P<0 \cdot 05\right.$ for $10^{-7} \mathrm{M}, P<0 \cdot 05$ for $10^{-8} \mathrm{M}$, $P<0.05$ for $10^{-9} \mathrm{M}, \quad P<0 \cdot 05$ for $\left.10^{-10} \mathrm{M}(0 \cdot 1 \mathrm{nM})\right)$. Hence, no dose-response was seen with UCN inducing hsp90 at all concentrations. However, stimulation of the cardiac myocytes with UCN at subnanomolar concentrations $\left(10^{-12} \mathrm{M} \quad(0 \cdot 001 \mathrm{nM}), \quad 10^{-11} \mathrm{M}(0 \cdot 01 \mathrm{nM})\right)$ failed to increase hsp 90 protein expression. UCN induction of hsp90 protein was inhibited by PD at all concentrations, as expected. The Western blots were scanned and the fold increase in hsp 90 protein expression by UCN is summarised in Table 1.

\section{UCN cardioprotection requires protein synthesis}

To determine whether UCN-mediated cardioprotection requires de novo protein synthesis, UCN was cultured with the cardiac cells for 1 and $24 \mathrm{~h}$ with and without cycloheximide (CYC) or PD prior to lethal ischaemia. Following exposure of the cells to simulated hypoxia/ischaemia, cell survival was assessed using trypan blue exclusion (Table 2).

UCN was protective against cell death when added to the cells at both $1 \mathrm{~h}(P<0001)$ and $24 \mathrm{~h}(P<0 \cdot 001)$ before lethal simulated ischaemia, compared with the untreated cells (NT) exposed to ischaemia. The cardioprotective effects of UCN were inhibited by CYC compared with UCN-treated cells alone, when UCN and CYC were added to the cardiac myocytes $1 \mathrm{~h}(P<0.05)$ and $24 \mathrm{~h}$ $(P<0 \cdot 05)$ before lethal ischaemia (Table 2$)$. The cardioprotective effects of UCN were inhibited by PD98059 for both the 1 -h $(P<0.05)$ and $24-\mathrm{h}(P<0.001)$ pre-treatment with UCN compared with the UCN-treated cells alone. PD had no effect on cell survival when administered alone prior to ischaemic injury alone. However, CYC administered $1 \mathrm{~h}$ prior to ischaemia exhibited some cardioprotection $(P<0 \cdot 001)$ compared with the untreated

Table 2 UCN cardioprotection requires protein synthesis. The data are representative of mean values \pm S.D. of the percentage of blue cells (dead) over white (live) plus blue cells ( $n=8$ for each treatment)

Ischaemic cell death $(\%)$

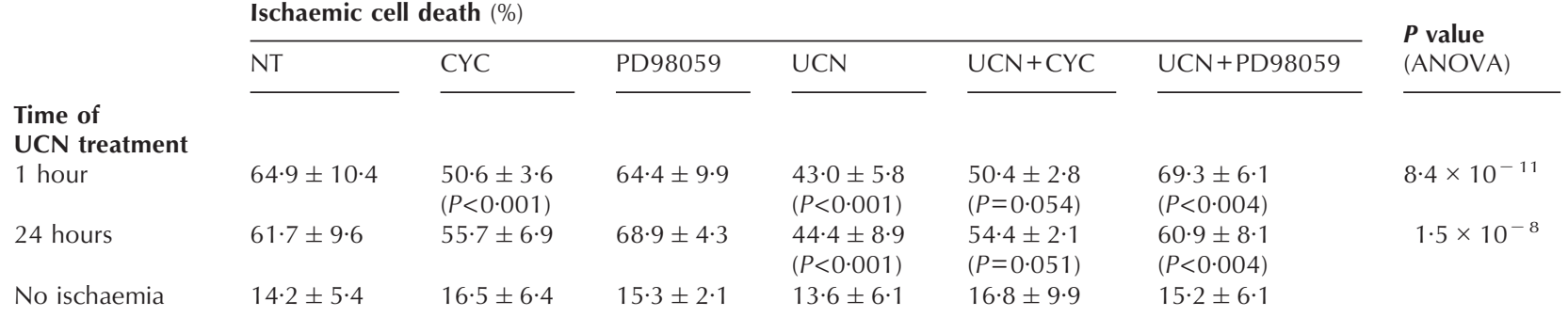

To determine whether UCN mediated cardioprotection requires de novo protein synthesis, UCN was cultured with the cardiac cells for 24 hours with and without cycloheximide (CYC) or PD prior to lethal ischaemia. Following exposure of the cells to simulated hypoxia/ischaemia, cell survival was assessed using trypan blue exclusion. CYC significantly protected the cardiac myocytes from ischaemic injury after 1 hour of treatment $(P<0 \cdot 001)$ compared with the untreated cells (NT), as did UCN alone. UCN in the presence of CYC (UCN + CYC) inhibited the UCN-mediated cardioprotective effect at both 1 hour $(P=0 \cdot 054)$ and 24 hours $(P=0 \cdot 051)$. PD significantly inhibited the UCN-mediated cardioprotective effect $(P<0 \cdot 004)$ compared with UCN-treated cells alone at both 1 and 24 hours of treatment. 
(a) UCN CYC+ CYC NT UCN

\section{Hsp 90-}

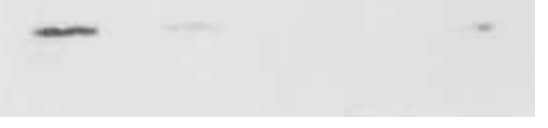

(b)

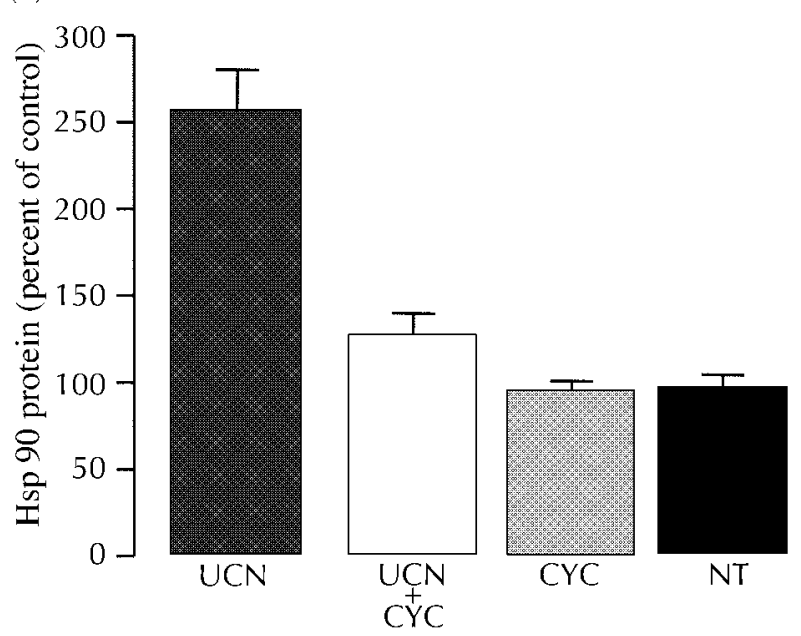

Figure $3 \mathrm{UCN}$ induction of hsp90 is inhibited by cycloheximide (CYC). Cardiac myocytes were incubated with UCN, CYC and CYC with UCN (CYC+UCN). (a) Typical blot; (b) the result of densitometric scanning of three replicate blots. CYC significantly reduced the basal level of hsp90 protein synthesis (CYC) compared with untreated cells (NT). CYC inhibited the $\mathrm{UCN}$-mediated increase in hsp90 protein expression $(\mathrm{CYC}+\mathrm{UCN})$.

cells (Table 2), although this was less than observed with UCN alone. The extent of cell death observed with UCN and CYC was similar to that observed with CYC alone, indicating that protein synthesis is likely to be required for the cardioprotective effect of UCN. However, the protective effect of CYC alone means this cannot be proven unequivocally. CYC administered to cardiac myocytes alone had no effect on cell survival in control conditions: $14 \cdot 3 \pm 5 \cdot 4 \%(n=8)$ of untreated cells that were cultured in a normoxic environment failed to exclude trypan blue compared with $16 \cdot 5 \% \pm 6 \cdot 4 \quad(n=8)$ of cells that were cultured in a normoxic environment in the presence of CYC. The induction of hsp90 by UCN was inhibited by CYC (Fig. 3a,b).

These data suggest that in addition to MEK1/2, protein synthesis is required to mediate both the induction of hsp90 and the cardioprotective effect of UCN. A similar inhibition of protection with a lower dose of PD of $5 \mu \mathrm{M}$ was also observed in accordance with our earlier results (Brar et al. 2000). No effect of UCN on activation of other kinases such as p38 or JNK was observed (data not shown), in agreement with our previous observation that UCN fails to induce phosphorylation and consequent activation of JNK and p38 (Brar et al. 2000).

\section{UCN-mediated increase in hsp 90 protein is not inhibited by actinomycin D}

An increase in expression of hsp90 by UCN occurs within 10 min of treatment (Fig. 1) similar to the increase in hsp90 protein expression induced by CT-1 (Railson et al. 2000). CT-1 induction of hsp 90 appears to be regulated at a post-transcriptional level (Railson et al. 2000). To determine whether the increase in hsp90 protein expression by UCN requires de novo transcription, cardiac myocytes were incubated with and without UCN for $1 \mathrm{~h}$ together with the transcriptional inhibitor actinomycin D (ACT). Due to the decrease in the levels of specific proteins such as actin induced by ACT, these experiments were carried out using extracts prepared from equal numbers of cells subjected to each treatment. Figure 4 shows a $2 \cdot 7$-fold increase in expression of hsp90 by UCN alone compared with the untreated control. Incubation of ACT and UCN still revealed a strong 3.6-fold increase in hsp 90 protein expression by UCN compared with the ACT-treated cells alone, suggesting that hsp90 protein expression by UCN may occur, at least in part, by a post-transcriptional mechanism. The levels of hsp 90 protein are less in the UCN+ACT-treated cells than the UCN-treated cells alone prior to equalisation for actin (Fig. 4(a)). This is due to ACT decreasing the basal level of protein expression, as shown by a decrease in total cellular actin levels. As expected, UCN failed to change the expression of hsp70, although it did decrease with ACT reflecting a general decrease in protein synthesis in the ACT-treated cells (Fig. 4).

To investigate whether UCN-mediated cardioprotection requires gene transcription, cells were incubated with UCN and ACT prior to lethal ischaemia. The percentage of cell death in the untreated cells exposed to lethal ischaemia (NT) for the 1-h and 24-h treatments prior to lethal ischaemia were $64.9 \%$ and $61 \cdot 7 \%$ respectively (Table 3). UCN significantly reduced the percentage of cell death to $43 \cdot 0 \%(P<0 \cdot 001)$ and $44 \cdot 4 \%(P<0 \cdot 001)$ for the 1-h and 24-h pre-incubations with UCN respectively compared with the untreated ischaemic control cells. ACT alone reduced the percentage of cell death to $45.5 \%$ $(P<0 \cdot 01)$ and $55.8 \%(P<0 \cdot 05)$ for the 1 -h and $24-\mathrm{h}$ pre-incubations respectively compared with the untreated ischaemic control cells. ACT had no inhibitory effect on $\mathrm{UCN}$-mediated cardioprotection at the 1-h time point but at the 24-h treatment with UCN, ACT inhibited UCNmediated cardioprotection. However, it is difficult to determine whether gene transcription is required for the UCN cardioprotective effects as ACT is itself cardioprotective (Table 3). This, therefore, prevents a firm conclusion that ACT can prevent the protective effect of $\mathrm{UCN}$ at $24 \mathrm{~h}$. 
(a) UCN
$+\mathrm{ACT}$

UCN

ACT

NT

Hsp 90

Hsp 70

ACTIN
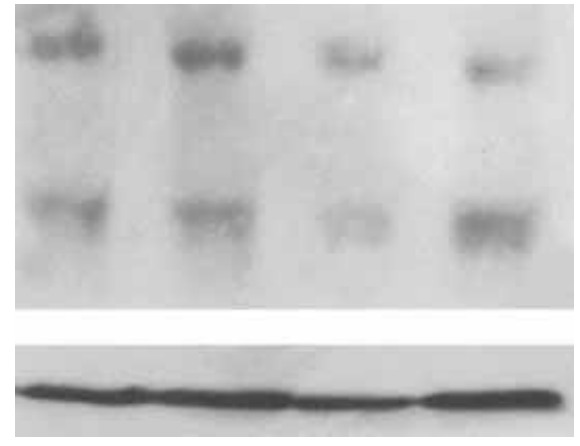

(b)

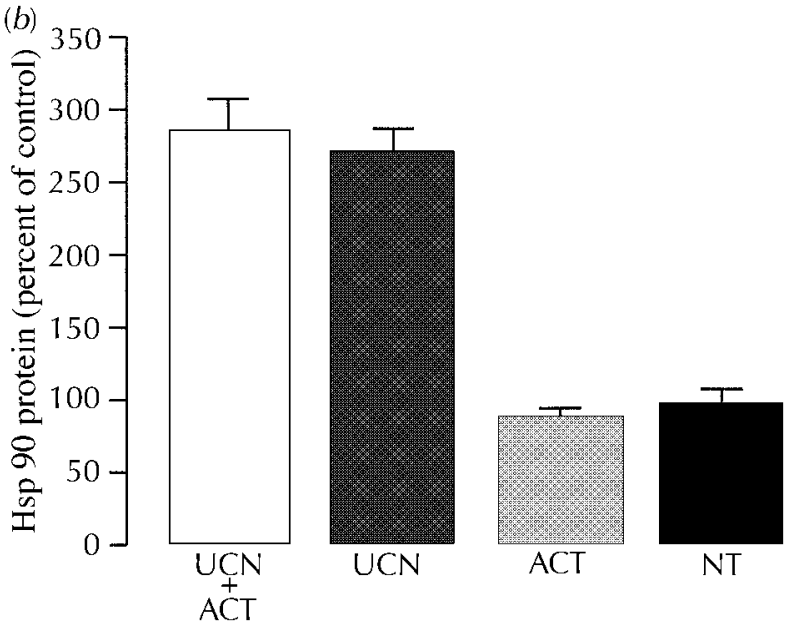

Figure $4 \mathrm{UCN}$ increase in hsp90 protein is not inhibited by actinomycin D (ACT). To determine whether hsp90 expression by $\mathrm{UCN}$ is a post-transcriptional regulated event, cardiac myocytes were incubated with (UCN) and without UCN (NT) for 60 min without or with the RNA synthesis inhibitor actinomycin D $(\mathrm{UCN}+\mathrm{ACT})$. Cells were also treated with ACT alone (ACT). Cell lysates were harvested. As for all the immunoblots, an aliquot of cell lysate $(5 \mu \mathrm{l})$ was retained to measure cell protein content, so protein levels between samples were equalised prior to electrophoresis. The immunoblot was probed with a mixture of hsp90 and hsp70 antibodies. (a) Typical blot for hsp90, hsp70 and actin. (b) Result of densitometric scanning and equalisation for actin levels for three replicate blots.

\section{UCN does not activate hsp 90 promoter reporter constructs}

To further investigate whether the hsp90 protein expression increase induced by $\mathrm{UCN}$ is due to posttranscriptional regulation, hsp $90 \alpha$ and hsp $90 \beta$ CAT promoter reporter constructs were transfected into cardiac myocytes. No significant increase in promoter activity was observed following a 2-h or 24-h treatment with UCN (Table 4). As expected, these promoters were activated by heat shock as the hsp $90 \beta$ and hsp $90 \alpha$ promoter activity increased by $3 \cdot 2$-fold and $4 \cdot 1$-fold respectively from nonheat shocked cells. Hence, UCN failed to activate the hsp $90 \beta$ and hsp $90 \alpha$ promoter reporter constructs. It is possible that these reporter constructs may simply lack the critical sequences needed to produce increased transcription in response to UCN. However, these data and the data with ACT suggest that the increase in hsp 90 protein induced by UCN is likely to be mediated by post-transcriptional regulation.

\section{Discussion}

We have previously demonstrated that MEK1/2 is necessary for the cardioprotective effect of UCN (Brar et al. 2000). The current study presents new findings in relation to the cardioprotective mechanism of UCN and reports for the first time that UCN causes a rapid increase in expression of hsp90, but not hsp70. The expression of hsp90 by UCN is inhibited by PD98059, a MEK1/2 inhibitor. The protein synthesis inhibitor, CYC, decreases the basal and UCN-mediated induced levels of hsp90 protein and appears to inhibit UCN-mediated cardioprotection. The increased expression of hsp 90 protein by UCN is not inhibited by the transcriptional inhibitor ACT and neither does UCN activate the hsp90 $\alpha$ and the hsp90 $\beta$ CAT promoters. Similarly, ACT appears not to inhibit cardioprotection by UCN given for one hour. These data suggest that MEK1/2 and de novo protein synthesis are required for the cardioprotective effect of UCN. This study is similar to a previous study whereby isolated perfused rat hearts were exposed to repetitive episodes of brief ischaemia which induces myocardial adaptation to prolonged global ischaemia, a phenomenon known as ischaemic preconditioning (Rowland et al. 1997). CYC and ACT were injected intraperitoneally $3 \mathrm{~h}$ prior to ischaemia and CYC inhibited the cardioprotective effect of preconditioning whereas ACT had no effect.

From our data for hsp 90 promoter studies, the increase in hsp90 by UCN appears to be a post-transcriptional regulated event. The survival effects of UCN are likely to be due to a signal cascade set off by ERK1/2, p42/44 which results in post-transcriptionally mediated elevation of hsp90 and possibly other protective proteins. UCN caused a rapid increase in hsp90 protein synthesis following $10 \mathrm{~min}$ of stimulation. Similarly, our group has reported a rapid induction in the expression of hsp90 in rat neonatal rat cardiac myocytes by CT -1 , following $10 \mathrm{~min}$ of treatment (Railson et al. 2000). Similar to our experiments with UCN, expression of hsp90 induced by CT-1 was sustained for up to $24 \mathrm{~h}$ and the mechanism of induction appeared to be via a post-transcriptional mechanism. Hsp90 protein expression is preferentially increased compared with hsp70 levels which are not modified by UCN. In cardiac myocytes that are unstressed, the levels of hsp70 (inducible form) are low or are unable to be detected. A previous study has reported a 10-fold increase in the expression of the inducible form of hsp70 following 
Table 3 The effect of actinomycin D (ACT) on UCN-mediated cardioprotection as measured by trypan blue exclusion. The data represent the percentage of blue cells (dead) over white cells (live) plus blue cells ( $n=8$ for each treatment)

\begin{tabular}{|c|c|c|c|c|c|}
\hline & \multicolumn{4}{|c|}{ Ischaemic cell death (\%) } & \multirow{2}{*}{$\begin{array}{l}\boldsymbol{P} \text { value } \\
\text { (ANOVA) }\end{array}$} \\
\hline & $\overline{N T}$ & $\mathrm{ACT}$ & UCN & $\mathrm{UCN}+\mathrm{ACT}$ & \\
\hline \multicolumn{6}{|l|}{$\begin{array}{l}\text { Time of } \\
\text { UCN treatment }\end{array}$} \\
\hline 1 hour & $64 \cdot 9 \pm 10 \cdot 4$ & $\begin{array}{l}45 \cdot 5 \pm 5 \cdot 6 \\
(P<0 \cdot 01)\end{array}$ & $\begin{array}{l}43 \cdot 0 \pm 5 \cdot 8 \\
(P<0 \cdot 001)\end{array}$ & $\begin{array}{l}41 \cdot 9 \pm 4 \cdot 8 \\
(P=0 \cdot 63)\end{array}$ & $7 \cdot 4 \times 10^{-10}$ \\
\hline 24 hours & $61 \cdot 7 \pm 9 \cdot 6$ & $\begin{array}{l}55 \cdot 8 \pm 6 \cdot 5 \\
(P<0 \cdot 05)\end{array}$ & $\begin{array}{l}44 \cdot 4 \pm 8 \cdot 9 \\
(P<0 \cdot 001)\end{array}$ & $\begin{array}{l}55 \cdot 8 \pm 5 \cdot 9 \\
(P=0 \cdot 048)\end{array}$ & $1.03 \times 10^{-7}$ \\
\hline No ischaemia & $14 \cdot 2 \pm 5 \cdot 4$ & $15 \cdot 6 \pm 11 \cdot 9$ & $13 \cdot 6 \pm 6 \cdot 1$ & $17 \cdot 3 \pm 2 \cdot 5$ & \\
\hline \multicolumn{6}{|c|}{$\begin{array}{l}\text { To determine whether transcription of DNA is required for UCN mediated cardioprotection, cardiac } \\
\text { myocytes were incubated with (UCN) and without UCN (NT) for } 1 \text { hour and } 24 \text { hours with the RNA } \\
\text { synthesis inhibitor ACT (UCN+ACT). Following exposure of the cells to simulated hypoxia/ischaemia, } \\
\text { cell survival was assessed using trypan blue exclusion. The significance for cardioprotection is compared } \\
\text { with the untreated control (NT) for the ACT and UCN alone treatments. ACT failed to inhibit the } \\
\text { UCN-mediated protection at } 1 \text { hour treatment (ACT }+U C N, P=0 \cdot 63 \text { ) compared with UCN alone. ACT } \\
\text { inhibited the UCN-mediated protection at } 24 \text { hours of treatment (ACT+UCN, } P=0 \cdot 048 \text { ) compared with } \\
\text { UCN alone. }\end{array}$} \\
\hline
\end{tabular}

stressful stimuli (Su et al. 1998). This study clearly reports no significant changes in inducible hsp70 protein expression by UCN. CT-1 increases the expression of both hsp90 and hsp70 by a post-transcriptional mechanism, independent of the MEK1/2 signalling pathway (Railson et al. 2000). In contrast to CT-1, the cardioprotective effect of CT-1 is independent of de novo protein synthesis, but like UCN it is dependent on the MEK1/2 signalling cascade. This questions the relevance of hsp 90 protein synthesis in CT-1-mediated cardioprotection. Whether the cardioprotective effect of UCN is mediated by the induction of hsp90 is unconfirmed; however, the fact that inhibition of MEK1/2 and protein synthesis inhibit both UCN-mediated cardioprotection and hsp90 protein expression suggests a possible link.

The post-transcriptional increase in hsp 90 by $\mathrm{UCN}$ is clearly different from the general mechanism of hsp induction by stressful stimuli, which is mainly based on transcriptional activation. However, cisplatin has been shown to induce hsp25 protein synthesis at the level of mRNA translation without any changes in hsp25 gene transcription in tumour cells (Gotlhardt et al. 1996). Cisplatin treatment does not significantly increase the oligomerisation of HSF1 and 2, hsp25 promoter activity or hsp 25 mRNA stability as judged by cross-linking experiments, reporter gene assay and Northern blot analysis. UCN induction of hsp90 in cardiac myocytes may be mediated by a similar mechanism to the cisplatin-induced increase in hsp25 protein in tumour cells involving enhanced translation of the hsp 90 mRNA. However, rapamycin which inhibits the p70 S6 kinase that can regulate translation had no effect on the UCN-mediated increase in hsp90 protein expression (B Brar, unpublished observations). The transport of

Table 4 UCN does not activate hsp90 promoter reporter constructs. The data are represented as relative fold increase from NT CAT activity/B-gal activity/mg total cellular protein, $n=6$ per treatment. The data points represent means of 6 independent experiments \pm S.D.

\begin{tabular}{|c|c|c|c|}
\hline & Hsp90a & Hsp90ß & PBLCAT2 \\
\hline \multicolumn{4}{|l|}{ Treatment } \\
\hline NT & $1 \cdot 00 \pm 0 \cdot 11$ & $1 \cdot 00 \pm 0 \cdot 04$ & $1 \cdot 00 \pm 0 \cdot 04$ \\
\hline UCN 2 hours & $1 \cdot 27 \pm 0 \cdot 14(P=0 \cdot 7)$ & $1.05 \pm 0.03(P=0.91)$ & $1 \cdot 09 \pm 0.03$ \\
\hline UCN 24 hours & $1 \cdot 184 \pm 0 \cdot 12(P=0 \cdot 2)$ & $1 \cdot 00 \pm 0.04(P=0.9)$ & $1 \cdot 247 \pm 0.16(P=0.6)$ \\
\hline Heat shock & $4 \cdot 1 \pm 0 \cdot 2$ & $3 \cdot 2 \pm 0 \cdot 2(P=0 \cdot 043)$ & $1 \cdot 00 \pm 0 \cdot 12$ \\
\hline
\end{tabular}

Hsp90 $\alpha$ and Hsp90 $\beta$ CAT promoter reporter constructs were transfected into cardiac myocytes. A CMV expression vector for B-gal was co-transfected into the cells and $\beta$-galactosidase activity was used to control for transfection efficiency. The cells were untreated (NT) or treated with UCN for 2 or 24 hours or exposed to heat shock. PBLCAT2 alone was transfected into the cardiac myocytes as a control for transfection. Significance is calculated for fold increase in promoter activity from the NT control for each expression vector using $\boldsymbol{T}$-test. 
hsp90 mRNA to the cytoplasm and/or hsp90 mRNA stability may be increased or modified by UCN to allow prolonged translation of the protein. In addition, hsp90 protein stability may increase after UCN treatment and may be reflected in alterations of oligomerisation or compartmentation.

Hsp90 is normally abundant in the cytoplasm of normal cardiac cells and levels of the protein increase considerably in response to stress (Heads et al. 1995). We have shown previously in our laboratory that over-expression of the hsp $90 \beta$ gene alone by transfection in the H9c2 cardiac cell line (Heads et al. 1995) and primary cardiac myocytes (Cumming et al. 1996) protects the cells from lethal heat shock, but not from hypoxic/ischaemic injury. This is in contrast to hsp70 which protects the cardiac cells from both stresses. It may be possible that in these experiments the transfected hsp90 $\beta$ may not have been targeted to the effective cellular compartment to mediate cardioprotection. In addition, these experiments involved the transfection of hsp90 $\beta$ and cardioprotection may require hsp $90 \alpha$ as well as or instead of hsp $90 \beta$. Interestingly, the alpha isoform of hsp90 has been shown to be induced in response to reperfusion in brain and heart, suggesting it is this protein that is cytoprotective (Kawagoe et al. 1993, Nishizawa et al. 1996). UCN may also result in the activation of a protein which is required for the full activation of hsp90. Further studies showing the internal localisation of hsp90 following UCN treatment, and transient transfection experiments involving inhibition of hsp90 synthesis or activity using antisense or dominant negative mutants of hsp90 will need to be conducted to determine whether hsp90 is cardioprotective.

There are no previous reports of any member of the CRF family of peptides increasing the levels of hsp protein expression in any cell type. As UCN and the CRF family of peptides mediate the endocrine response to stress and hsps are elevated at a cellular level in response to stress, we propose a novel connection between UCN and hsps in mediating the paracrine/autocrine/cellular response to stress in cardiac cells. Using specific cytokines, hormones and stresses that increase hsp 90 protein expression it should be possible to dissect the distinct signalling pathways that mediate hsp regulation, and gain greater understanding as to how hsp90 and hsp70 directly mediate cardioprotective responses. Moreover, these studies suggest a positive correlation between hsp90 and cardioprotection mediated by UCN.

\section{Acknowledgements}

The authors would like to thank the British Heart Foundation for funding this work. J Railson was funded by a BHF PhD Studentship and A Stephanou is a BHF Intermediate Fellowship holder.

\section{References}

Benjamin IJ \& McMillan RD 1998 Stress (heat shock) proteins: molecular chaperones in cardiovascular biology and disease. Circulation Research 83 117-132.

Bradford MA 1976 A rapid and sensitive method for quantification of microgram quantities of protein utilising the principle of protein dye binding. Analytical Biochemistry 72 248-254.

Brar BK, Stephanou A, Okosi A, Lawrence KM, Chowdry HS, Knight RK \& Latchman DS 1999a CRH-like peptides protect cardiac myocytes from lethal ischaemic injury. Molecular and Cellular Endocrinology 158 55-63.

Brar BK, Stephanou A, Wagstaff MGD, Coffin RS, Marber MS, Engelmann G \& Latchman DS 1999 b Heat shock proteins delivered with a virus vector can protect cardiac cells against apoptosis as well as against thermal or ischaemic stress. Journal of Molecular and Cellular Cardiology 31 135-146.

Brar BK, Jonassen AK, Stephanou AS, Santilli G, Railson JE, Knight RA, Yellon DM \& Latchman DS 2000 Urocortin protects against ischaemic and reperfusion injury via a MAPK-dependent pathway. Journal of Biological Chemistry 275 8508-8514.

Brar BK, Stephanou AS, Liao Z, O'Leary RM, Pennica D, Yellon DM \& Latchman DS 2001 Cardiotrophin-1 can protect cardiac myocytes from injury when added both prior to simulated ischaemia and at reoxygenation. Cardiovascular Research 51 265-274.

Cumming DV, Heads RJ, Watson A, Latchman DS 1996 Differential protection of primary rat cardiocytes by transfection of specific heat stress proteins. Journal of Molecular and Cellular Cardiology 28 $2343-2349$.

Denis M \& Gustafsson J 1989 The Mr approximately 90000 heat shock protein: an important modulator of ligand and DNA-binding properties of the glucocorticoid receptor. Cancer Research 49 2275S-2281S.

Dudley DT, Pang L, Decker SJ, Bridges AJ \& Saltiel AR 1995 A synthetic inhibitor of the mitogen-activated protein kinase cascade. PNAS 92 7686-7689.

Esumi K, Nishida M, Shaw D, Smith TW \& Marsh JD 1991 NADH measurements in adult rat myocytes during simulated ischaemia. American Journal of Physiology 260 1743-1752.

Gorman CM 1985 High efficiency gene transfer into mammalian cells. In DNA Cloning, A Practical Approach, pp134-190. Ed. DM Glover. Oxford, UK: IRL Press.

Gotlhardt R, Nerninger A \& Gastel M 1996 The anti-cancer drug cisplatin induces hsp25 in Enrlich Ascites tumour cells by a mechanism different from transcriptional stimulation influencing predominantly hsp 25 translation. International Journal of Cancer $\mathbf{6 6}$ 790-795.

Heads RJ, Yellon DM \& Latchman DS 1995 Differential cytoprotection against heat stress or hypoxia following expression of specific stress protein genes in myogenic cells. Journal of Molecualr and Cellular Cardiology 27 1669-1678.

Hickey E, Brandon SE, Smale G, Llyde D \& Weber LA 1989 Sequence and regulation of a gene encoding a human 89-kilodalton heat shock protein. Molecular and Cellular Biology 9 2615-2626.

Hutter JJ, Mestril R, Tam EK, Sievers RE, Dillmann WH \& Wolfe CLA 1996 Direct correlation between the amount of heat shock protein induced and the degree of myocardial protection. Circulation 94 1408-1411.

Kawagoe J, Abe K, Aoki M \& Kogure K 1993 Induction of HSP90 alpha heat shock mRNA after transient global ischaemia in gerbil hippocampus. Brain Research 621 121-125.

Kim J, Neuda A, Meng YH, Dynan WS \& Mivechi NF 1997 Analysis of the phosphorylation of human heat shock transcription factor-1 by MAP-kinase family members. Journal of Cellular Biochemistry 67 43-54.

Marber MS, Latchman DS, Walker JM \& Yellon DM 1993 Cardiac stress protein elevation 24 hours after brief ischaemia or heat stress is associated with resistance to myocardial infarction. Circulation $\mathbf{8 8}$ 1264-1272. 
Marber MS, Mestril R, Chi SH, Sayen MR, Yellon DM \& Dillmann WH 1995 Over-expression of the rat inducible $70 \mathrm{kDa}$ heat shock protein in a transgenic mouse increases the resistance of the heart to ischaemic injury. Journal of Clinical Investigation 95 1446-1456.

Martin JL, Mestril R, Hilal-Dandan R, Brunton LL \& Dillmann WH 1997 Small heat shock proteins and protection against ischaemic injury in cardiac myocytes. Circulation 96 4343-4348.

Mestril R, Chi SH, Sayen MR, O’Reilly K \& Dillmann WH 1994 Expression of inducible stress protein 70 in heart myogenic cells confers protection against simulated ischaemia-induced injury. Journal of Clinical Investigation 93 759-767.

Metz K, Ezernieks J, Sebald W \& Duschl A 1996 Interleukin-4 upregulates heat shock protein Hsp90 alpha and enhances transcription of a reporter gene coupled to a single heat shock element. FEBS Letters 385 25-28.

Nakai A, Kawazoe Y, Tanabe M, Nagata K \& Morimoto RI 1995 The DNA binding properties of two heat shock factors, HSF1 and HSF3, are induced in the avian erythroblast cell line HD6. Molecular and Cellular Biology 15 5268-5278.

Nishizawa J, Nakai A, Higashi T, Tanabe M, Nomoto S, Matsuda K, Ban T \& Nagata K 1996 Reperfusion causes significant activation of heat shock transcription factor 1 in ischaemic rat heart. Circulation 94 2185-2192.

Okosi A, Brar BK, Chan M, D’Souza L, Smith E, Stephanou A, Chowdry HS, Latchman DS \& Knight RK 1998 Expression and protective effects of urocortin in cardiac myocytes. Neuropeptides $\mathbf{3 2}$ 167-171.

Plumier JC, Ross BM, Curie RW, Angelidis CE, Kazlaris H, Kollias G \& Pagoulatos GN 1995 Transgenic mice expressing the human heat shock protein 70 have improved postischaemic myocardial recovery. Journal of Clinical Investigation 95 1854-1860.

Radford NB, Fina M, Benjamin IJ, Moreadith RW, Graves KH, Zhao P, Gavva S, Wiethoff A, Sherry AD, Malloy CR \& Williams RS 1996 Cardioprotective effects of $70 \mathrm{kDa}$ heat shock protein in transgenic mice. PNAS 93 2339-2342.

Railson JE, Lawrence KM, Stephanou A, Brar BK, Pennica D \& Latchman DS 2000 Cardiotrophin-1 reduces stress induced heat shock protein production in cardiac myocytes. Cytokine $\mathbf{1 2}$ 1741-1744.

Rebbe NF, Ware J, Bertina RM, Modrich P \& Stafford DW 1987 Nucleotide sequence of a cDNA for a member of the human 90-kDa heat shock protein family. Gene 53 235-245.

Redmond T, Sanchez ER, Bresnick EH, Schlesinger MJ, Toft DO, Pratt WB \& Welsh MJ 1989 Immunofluorescence co-localisation of the $90-\mathrm{kDa}$ heat-shock protein and microtubules in interphase and mitotic mammalian cells. European Journal of Cellular Biology $\mathbf{5 0}$ $66-75$.

Rowland RT, Meng X, Cleveland JC, Meldrum DR, Harken AH \& Brown JM 1997 Cardio-adaptation induced by cyclic ischaemic preconditioning is mediated by translational regulation of de novo protein synthesis. Journal of Surgical Research 71 155-160.

Simpson P \& Savion S 1982 Differentiation of rat myocytes in single cell cultures with and without proliferating non-myocardial cells. Circulation Research 50 101-116.

Stephanou A, Brar BK, Heads R, Knight RD, Marber MS, Pennica D \& Latchman DS 1998 Cardiotrophin-1 induces heat shock protein accumulation in cultured cardiac cells and protects them from stressful stimuli. Journal of Molecular and Cellular Cardiology 30 849-855.

Stephanou A, Brar BK, Scarabelli TM, Jonassen AK, Yellon DK, Marber MS, Knight RA \& Latchman DS 2000 Ischaemia-induced STAT-1 expression and activation plays a critical role in cardiac myocyte apoptosis. Journal of Biological Chemistry 275 10002-10008.

Su CY, Chong KY, Owen OE, Dillmann WH, Chang C \& Lai CC 1998 Constitutive and inducible hsp70s are involved in oxidative resistance evoked by heat shock or ethanol. Journal of Molecular and Cellular Cardiology 30 587-598.

Teshima S, Rokutan K, Takahashi M, Nikawa T \& Kishi K 1996 Induction of heat shock proteins and their possible roles in macrophages during activation by macrophage colony-stimulating factor. Biochemical Journal 315 497-504.

Vale W, Spiess J, Rivier C \& River J 1981 Characterisation of a 41-residue ovine hypothalamic peptide that stimulates secretion of corticotrophin and $\beta$-endorphin. Science 213 1394-1397.

Vaughan J, Donaldson C, Bittencourt J, Perrin MH, Lewis K, Sutton S, Chen R, Turnbull AV, Lovejoy D, Rivier C, Rivier J, Sawchenko PE \& Vale W 1995 Urocortin, a mammalian neuropeptide related to fish urotensin 1 and to corticotrophin-releasing factor. Nature 378 287-292.

Xiao H \& Lis JT 1988 Germline transformation used to define key features of heat shock response elements. Science 239 1139-1142.

Received 26 September 2001 Accepted 9 October 2001 